\title{
Effect of Surface Sandblasting and Turning on Compressive Strength of Thin 316L Stainless Steel Shells Produced by Laser Powder Bed Fusion
}

\author{
Bharat Mehta ${ }^{1, *(1)}$, Eduard Hryha ${ }^{1}$, Lars Nyborg ${ }^{1}$, Frederic Tholence ${ }^{2}$ and Erik Johansson ${ }^{2}$ \\ 1 Department of Industrial and Materials Science, Chalmers University of Technology, \\ 41296 Göteborg, Sweden; hryha@chalmers.se (E.H.); lars.nyborg@chalmers.se (L.N.) \\ 2 ABB Corporate Research, 72226 Västerås, Sweden; frederic.tholence@se.abb.com (F.T.); \\ erik.x.johansson@se.abb.com (E.J.) \\ * Correspondence: bharat.mehta@chalmers.se; Tel.: +46-(0)31-772-1534
}

check for

updates

Citation: Mehta, B.; Hryha, E.; Nyborg, L.; Tholence, F.; Johansson, E. Effect of Surface Sandblasting and Turning on Compressive Strength of Thin 316L Stainless Steel Shells Produced by Laser Powder Bed Fusion. Metals 2021, 11, 1070. https://doi.org/10.3390/met11071070

Academic Editors: Thomas Niendorf, Matteo Benedetti and Antonio Mateo

Received: 16 June 2021

Accepted: 30 June 2021

Published: 2 July 2021

Publisher's Note: MDPI stays neutral with regard to jurisdictional claims in published maps and institutional affiliations.

Copyright: (c) 2021 by the authors. Licensee MDPI, Basel, Switzerland. This article is an open access article distributed under the terms and conditions of the Creative Commons Attribution (CC BY) license (https:/ / creativecommons.org/licenses/by/ $4.0 /)$.

\begin{abstract}
This study evaluates the effect of post-manufacturing treatment on the compressive performance of additively manufactured components. The components were thin cylindrical shells with an aspect ratio of 25:1 manufactured using laser powder bed fusion and that were then surface treated by means of sandblasting or turning. The as-printed and subsequently surface treated samples were uniaxially compressed until failure to depict the effect of the surface condition on the compressive mechanical behavior. The results show that as the surfaces became smoother via sandblasting, the average peak strength for buckling load improves negligibly $(0.85 \%)$, whereas this effect reaches $6.5 \%$ upon surface layer removal via turning. Through microstructural investigation and co-relating this with an understanding of processing conditions existing in manufacturing itself, this effect is seen to be linked to contour scanning causing softening of the surface region in a component.
\end{abstract}

Keywords: thin shells; additive manufacturing; compressive strength; surface layer effect

\section{Introduction}

Additive manufacturing (AM) is the process of joining materials to make parts from 3D model data, usually layer upon layer, as opposed to subtractive manufacturing and formative manufacturing methodologies [1]. Laser powder bed fusion (LB-PBF) is an additive manufacturing process in which thermal energy selectively fuses regions of a powder bed. This layer-by-layer fusion enables the manufacturing of complex structures such as lattices and thin-walled structures, which are very expensive when manufactured with other available techniques [2,3]. The microstructure of the produced material is quite different from conventional manufacturing. The LB-PBF materials are characterized by columnar grain structure, with characteristic fine cellular or dendritic structure inside the grains, following the thermal gradient defined by the building direction and laser scan direction. Such microstructure results in anisotropic properties and residual stresses in the as-printed parts. In the case of 316L stainless steel, the cellular sub-grain structure formed during manufacturing by means of AM are also known to enhance the yield strength to 470-530 MPa for LB-PBF produced samples in comparison with 250-290 MPa for as-cast products, while retaining considerable elongation properties [4-6]. One reason for this is the dislocation pile-up in the cellular walls with enrichment of $\mathrm{Mo}, \mathrm{Cr}$, and formation of nano-sized oxide inclusions rich in $\mathrm{Si}, \mathrm{Cr}, \mathrm{Mn}$, etc. [5]. Due to dislocation pile-up, the dislocation densities have been shown to reach $10^{10} \mathrm{~m}^{-2}$ in annealed AISI 3161 stainless steels to $1.14 \times 10^{15} \mathrm{~m}^{-2}$ in cell walls of LB-PBF fabricated samples, which is a similar condition to strain hardened steels [7-9]. Such microstructural features combined with the freedom of design enabled via AM create a material capable of enormous engineering potential. It entices several designers into developing products containing lattice structures, 
bionic designs, thin-wall structures, etc. to achieve new stiffness or strength targets and create better products $[10,11]$.

As such structures get thin, the surfaces become more important, and so-called "surface effects" become more critical to be understood from a microstructural point of view. In conventional manufacturing techniques, a generic size effect is established, which explains a reduction in yield strength due to the difference in dislocation cells between the surface to the interior of the part, which causes a change in the plastic regime [12,13]. For LB-PBF processed 316L stainless steel, it was shown that lowering the part thickness showed a drop in the yield strength $[14,15]$. A decrease in yield strength, ultimate tensile strength, and stiffness by nearly a factor of two was observed as part thickness was scaled down from $6.25 \mathrm{~mm}$ to $0.4 \mathrm{~mm}$. The reason for this was attributed to the surface roughness of the samples responsible for causing stress concentrations in very thin sections. The existing work on the effect of surface roughness on fatigue properties of AlSi10Mg and Ti-6Al-4V produced via LB-PBF $[16,17]$ where an improvement in fatigue properties was observed by post-manufacturing treatments such as shot peening and milling, respectively. In the case of Ti-6Al-4V samples, fatigue life improved from $300 \mathrm{MPa}$ to $750 \mathrm{MPa}$ after $3 \times 10^{7}$ cycles after milling operation was completed on as-printed samples. Some authors [18] have reviewed the effect of different post-processing methods such as turning, shot peening, finished machining, electrochemical polishing, laser polishing, and grinding on several LB-PBF processed materials and found a general increasing trend in tensile properties after these post-processing treatments.

While such studies provide a brief idea that surface roughness affects mechanical properties for materials processed via AM, there is little research elaborating this effect into compressive properties in thin shell structures. As shown in [19], when conventionally welded 316L structures were completely re-designed for AM, an increase in three times the specific buckling strength was achieved. The limitation for the study was the dropping yield strengths in thin tubes (aspect ratio as high as 100:1) under buckling, which, as pointed out before, was attributed to rougher surfaces and defects coming from additive manufacturing. However, surface roughness and higher defect per unit thickness did not completely explain this drop, as this drop stayed consistent after sandblasting the samples too, which should have improved the surface roughness. Additionally, as-printed LB-PBF 316L stainless steel was also seen to have near full density $(>99.9 \%)$ with negligible defects $[14,19]$.

Thus, it was predicted that apart from surface defects or surface roughness, there may be a relatively common processing-related factor causing this. This processing factor is anticipated to be contour scanning, which is performed before/after the bulk of the sample is scanned. It is usually performed with no offset, thus effectively re-melting the edge of the component twice. Contour scanning is completed to reduce surface/sub-surface defects and greatly improve the surface roughness of as-printed components. It is anticipated that this creates a composite-like structure where the surface zone becomes softer. Such an effect can be singled out only when the surface is completely removed with post-processing methods such as milling or turning. Hence, this study evaluated the role of sandblasting and turning on compressive properties of $316 \mathrm{~L}$ stainless steel components for applications in buckling-resistant thin-shell structures. Both sandblasting and turning were conducted to emphasize the negligible impact of surface roughness in yielding of the material and a larger effect of the softer surface layer itself. The objective of this study is to develop a better understanding of this softening effect and provide recommendations to be kept in mind when designing thin structures, particularly those which go under compressive loads.

\section{Materials and Methods}

\subsection{Material and Processing Parameters}

The 316L stainless steel powder with standard powder size (20-53 $\mu \mathrm{m}$ size distribution) was acquired from Höganäs $\mathrm{AB}$ [20]. The chemical composition is presented in Table 1. The CAD files were prepared using MAGICS v23 from Materialise and then sliced using EOS 
Print v2.0. They were printed in an EOS M290 machine (Electro Optical Systems GmbH Germany) with parameters for bulk scanning and contour scanning as mentioned in Table 2. Printing was completed with fixed $0.04 \mathrm{~mm}$ layer thickness, $80^{\circ} \mathrm{C}$ build plate temperature, $<0.1 \% \mathrm{O}_{2}$ content in argon atmosphere, hard steel re-coater blade, and a $67^{\circ}$ scan orientation between layers. Figure 1 shows a build plate after printing of all the samples, where three different cross-sections (as mentioned in Figure 2) can be seen. Post-printing, the samples were cut from build plate with a cold saw and two different post-AM treatments were conducted: sandblasting or turning. Sandblasting was completed on an IEPCO Peenmatic 750 with about 3 bars of pressure in a micro-blasting pistol unit with about $1 \mathrm{~s}$ of shot peening, and the turning was completed by means of a manual lathe machine (turning machine) under standard parameters. No other post-processing such as heat treatment or hot isostatic pressing (HIP) was completed on the components after printing.

Table 1. Composition of 316L stainless steel acquired from Höganäs AB (composition in wt\%) [20].

\begin{tabular}{ccccccccc}
\hline Fe & $\mathbf{C r}$ & $\mathbf{N i}$ & $\mathbf{M o}$ & $\mathbf{M n}$ & $\mathbf{S i}$ & $\mathbf{C}$ & $\mathbf{O}$ & $\mathbf{N}$ \\
\hline Bal. & $17 \%$ & $12 \%$ & $2.5 \%$ & $1.5 \%$ & $0.8 \%$ & $0.01 \%$ & $0.06 \%$ & $0.1 \%$ \\
\hline
\end{tabular}

Table 2. Laser processing parameters used for LB-PBF process.

\begin{tabular}{ccccc}
\hline & $\begin{array}{c}\text { Laser Power } \\
(\mathbf{W})\end{array}$ & $\begin{array}{c}\text { Laser Speed } \\
(\mathbf{m m} / \mathbf{s})\end{array}$ & $\begin{array}{c}\text { Hatch Distance } \\
(\mathbf{m m})\end{array}$ & $\begin{array}{c}\text { Layer Thickness } \\
(\mathbf{m m})\end{array}$ \\
\hline Bulk scanning & 214.2 & 928.1 & 0.1 & 0.04 \\
\hline Contour scanning & 150.2 & 514.9 & 0.1 & 0.04 \\
\hline
\end{tabular}

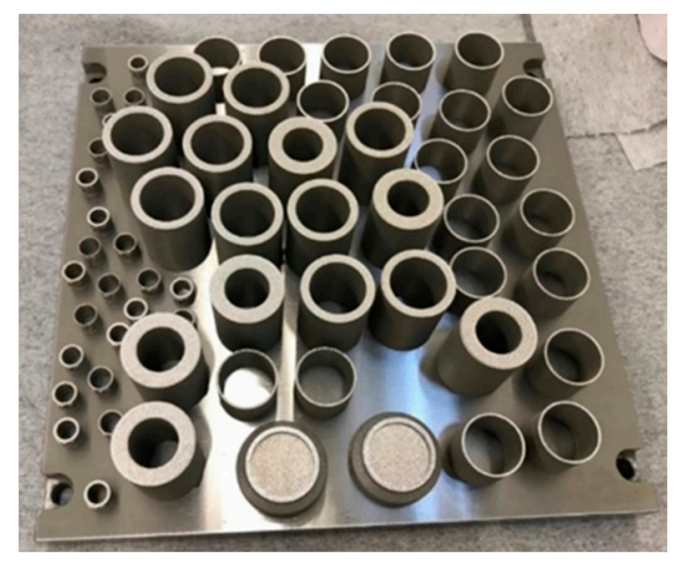

Figure 1. EOS M290 build plate with the cylindrical samples after printing.
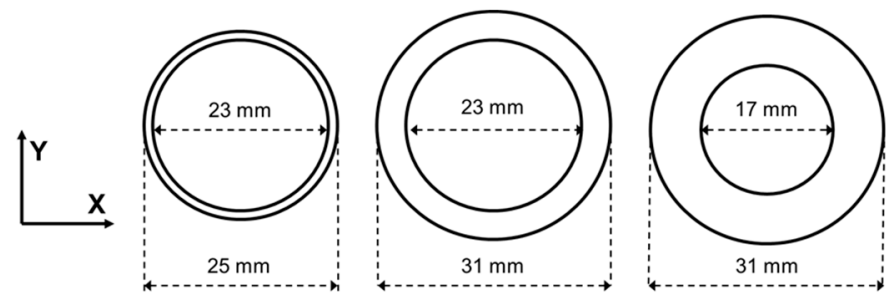

Figure 2. Sketch showing different cross-section diameters of cylinders designed according to post-AM treatment.

The schematic for scanning parameters, as seen in Figure 3, shows the XY section where a bulk scanning vector is shown, which usually scans a few $\mu \mathrm{m}$ more than the nominal part edge. This is then followed by a contour scanning which basically re-melts 
the whole surface region again (the surface region is the grey area in Figure 3, labeled as part edge). This is completed to have good surface finish and reduce defects after printing.

a)

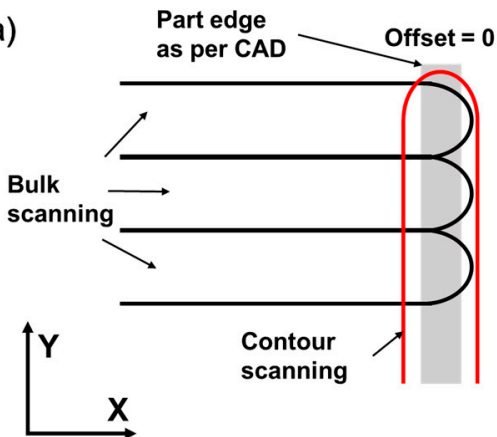

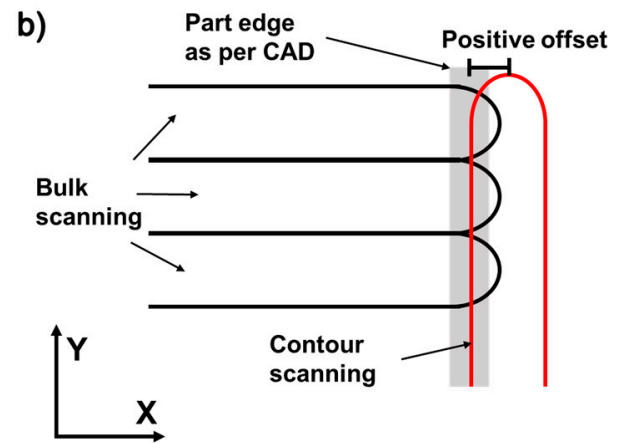

Figure 3. Schematic of bulk scanning vs. contour scanning on a sample. (a) Contour scanning without offset (default settings). (b) Contour scanning with a positive offset.

\subsection{Sample Definition}

To ensure that there was no discrepancy with other modes of compressive failure, the design of sample was set in a way that it buckles under material failure mode and not Euler buckling [21]. The critical load (P) for Euler buckling is usually calculated as in the equation below:

$$
\mathrm{P}=\left(\pi^{2} \times \mathrm{E} * \mathrm{I}\right) /\left(\mathrm{k} * \mathrm{l}^{2}\right)
$$

where $E$ is the Young's modulus $\left(\mathrm{N} / \mathrm{mm}^{2}\right)$, I the second moment of inertia $\left(\mathrm{mm}^{4}\right)$ and 1 is length of bar (mm), $\mathrm{k}$ is a constant (depending on loading conditions of the bar, for which $\mathrm{k}=4$ was taken here to represent the worst condition). For all the experiments, the values in Equation (1) are taken as $\mathrm{E}=2.1 \times 10^{5} \mathrm{~N} / \mathrm{mm}^{2}, \mathrm{I}=5438 \mathrm{~mm}^{4}$ and $\mathrm{l}=18 \mathrm{~mm}$, and the critical load becomes $8700 \mathrm{kN}$ for Euler buckling. For pure material failure, strength values are assumed to be the ones at the lower end of yield strength spectrum as recommended by EOS material datasheet [4] (470 MPa out of 470-530 MPa range), and the cross-sectional area is $75.39 \mathrm{~mm}^{2}$, which gives the failure load of $35.4 \mathrm{kN}$, which is two orders of magnitude less than the calculated Euler load. Hence, the cylindrical sections were designed in such a way to avoid Euler loads [19], and it was seen that yielding as mode of failure occurred in the samples, which is of interest as specific failure mode for the application.

Hence, when designing cylindrical samples with constant diameter to thickness ratio (25:1), the objective was kept to have a final outer diameter (Do) $=25 \mathrm{~mm}$, inner diameter $(\mathrm{Di})=23 \mathrm{~mm}$ and height $(\mathrm{h})=18.5 \pm 1 \mathrm{~mm}$ to avoid Euler buckling. Due to tolerances achieved during finish turning and cutting of samples after AM processing, variation in height of about $\pm 1 \mathrm{~mm}$ was acceptable. Since turning involves material removal, thicker samples with $3 \mathrm{~mm}$ additional measure on each face were produced and then turned down to meet the final dimensions as mentioned above. The samples were produced in a way that one surface was post-processed at one time to be able to identify the surface effect on the respective face. Surface roughness assessment, microstructural analysis, and uniaxial compression testing were performed on the samples. Table 3 shows the types of samples designed based on the different surface treatments addressed. Thus, three different cross-sections were designed in CAD for this study, as shown in Figure 2. The reason for that was to be able to conduct an effective post-AM treatment with consistent material removal and have similar final sample dimensions. 
Table 3. The different sets of post-AM treatments completed.

\begin{tabular}{cccc}
\hline S. No & Set & Part Printing + Post-Processing (If Any) & Dimensions (in CAD) \\
\hline 1 & Set A & As-printed & $\mathrm{D}_{\mathrm{o}}: 25 \mathrm{~mm}, \mathrm{D}_{\mathrm{i}}: 23 \mathrm{~mm}$ \\
\hline 2 & Set B & As-printed + outer side sandblasted & $\mathrm{D}_{\mathrm{o}}: 25 \mathrm{~mm}, \mathrm{D}_{\mathrm{i}}: 23 \mathrm{~mm}$ \\
\hline 3 & Set C & As-printed + both sides sandblasted & $\mathrm{D}_{\mathrm{o}}: 25 \mathrm{~mm}, \mathrm{D}_{\mathrm{i}}: 23 \mathrm{~mm}$ \\
\hline 4 & Set D & As-printed + outer side turned & $\mathrm{D}_{\mathrm{o}}: 31 \mathrm{~mm}, \mathrm{D}_{\mathrm{i}}: 23 \mathrm{~mm}$ \\
\hline 5 & Set E & As-printed + outer side turned + inner sandblast & $\mathrm{D}_{\mathrm{o}}: 31 \mathrm{~mm}, \mathrm{D}_{\mathrm{i}}: 23 \mathrm{~mm}$ \\
\hline 6 & Set F & As-printed + both sides turned & $\mathrm{D}_{\mathrm{o}}: 31 \mathrm{~mm}, \mathrm{D}_{\mathrm{i}}: 17 \mathrm{~mm}$ \\
\hline
\end{tabular}

\subsection{Surface Roughness Evaluation}

The surfaces of the samples were analyzed with a Sensofar S Neox instrument using a combination of confocal microscopy and focus variation, known as confocal fusion. The surface maps were created using Mountain Maps Premium V7.4.8872. The surface roughness maps were prepared on six different areas on three different kinds of samples, namely, as-printed, sandblasted, and machined. These six different areas were equally divided both along the circumference and the build direction of the samples and were taken on the outer surfaces of the samples only, as shown in Figure 4. This was performedbecause it was assumed that the surface roughness on the inner surface and outer surface for vertically printed cylindrical samples should be the same if the surface printing parameters are kept constant. These roughness values were also used as a correction factor for the identification of actual dimensions of the part after measuring with a vernier caliper.

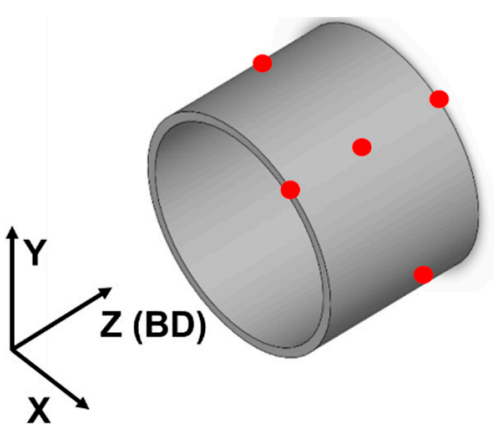

Figure 4. Isometric view of the tube showing all three directions. The red pointers represent the locations where surface roughness evaluation was conducted.

\subsection{Microstructure Evaluation and Mechanical Testing}

The samples for microstructural analysis were prepared using Struers Tegrapol 3 machine following the standard sample preparation for 316L stainless steels, where grinding was completed to make samples flat using foils of 200, 800, 1200, 2000 grit size followed by polishing with MD-mol cloth $(3 \mu \mathrm{m})$, MD-NAP cloth $(1 \mu \mathrm{m})$ and final polishing step with OP-S suspension to get highly polished surface. The electrochemical etching of the samples to reveal microstructure was completed using $20 \mathrm{wt} \%$ oxalic acid with Pt-electrode, under $3 \mathrm{~V}$ potential provided for about $10 \mathrm{~s}$. The SEM used was a Leo Gemini 1550 SEM equipped with field-emission gun. Grain orientation and texture were determined by means of an EBSD technique on OP-S polished samples using a Nordlys II detector (Oxford Instruments) and HKL Channel 5 data processing software. The step size was $1.5 \mu \mathrm{m}$, and acceleration voltage of $20 \mathrm{kV}$ was used for all the maps. All acquired orientation maps were processed, i.e., noise was taken away, and a noise reduction ( 7 nearest neighbors) was performed. The compression testing of the samples was completed at ABB Västerås, using a ZwickRoell universal testing machine, which was loaded with a $100 \mathrm{kN}$ load cell. Testing was completed at $1 \mathrm{~mm} / \mathrm{min}$ loading rate with displacement control, and measurement of the displacements were completed via the crosshead displacement sensor. One of the 
sets (Set F in Table 1) was repeated at Chalmers since one of the samples in Set F at ABB was performed incorrectly and thus removed from calculations. Hence, Set F consists of five data points (two conducted at ABB Västerås and three at Chalmers), whereas all other sets have three data points. The testing at Chalmers was conducted on an Instron $5500 \mathrm{R}$ universal testing machine which was loaded with a $100 \mathrm{kN}$ load cell and tested at $1 \mathrm{~mm} / \mathrm{min}$ loading rate with displacement control, and measurement of the displacements were completed via the crosshead displacement sensor, same as at ABB.

\section{Results}

\subsection{Surface Roughness}

The trend seen in Table 4 is representative of a reduction in overall surface roughness (Sa) after post-AM treatments. Figures 5-7 show representative surface maps for the three different types of samples. The final dimensions of the parts, as measured by a Vernier caliper and corrected with the surface measurements from confocal microscopy, are shown in Table 5.

Table 4. Summary of surface roughness results when taken at different locations on the samples by confocal microscopy.

\begin{tabular}{|c|c|c|c|c|c|c|c|}
\hline $\begin{array}{c}\text { Sample } \\
\text { Surface } \\
\text { Type }\end{array}$ & $\begin{array}{l}\text { Location } \\
\text { of Evalua- } \\
\text { tion }\end{array}$ & $\begin{array}{l}\text { Surface } \\
\text { Rough- } \\
\text { ness } S_{a} \\
(\text { in } \mu \mathrm{m})\end{array}$ & $\begin{array}{c}\text { Surface } \\
\text { Rough- } \\
\text { ness Peak } \\
S_{\mathrm{z}}(\text { in } \\
\mu \mathrm{m})\end{array}$ & $\begin{array}{c}\mathrm{R}_{\mathrm{z}} \\
\text { (Gaussian } \\
\text { Filter } \\
\text { 0.8 Mm; } \\
\text { Mean; } \\
\text { in } \mu \mathrm{m} \text { ) }\end{array}$ & $\begin{array}{c}\mathbf{R}_{\mathrm{a}} \\
\text { (Gaussian } \\
\text { Filter } \\
0.8 \mathrm{Mm} ; \\
\text { Mean; } \\
\text { in } \mu \mathrm{m} \text { ) }\end{array}$ & $\begin{array}{c}S_{a} \\
\text { (Average } \\
\text { in } \mu \mathrm{m} \text { ) }\end{array}$ & $\begin{array}{l}\text { Reduction } \\
\text { in } S_{a}\end{array}$ \\
\hline \multirow{2}{*}{$\begin{array}{c}\text { As- } \\
\text { printed }\end{array}$} & $\begin{array}{l}\text { Along } \\
\text { circumfer- } \\
\text { ence }\end{array}$ & 13.08 & 68.53 & 55.63 & 10.71 & \multirow{2}{*}{13.04} & \multirow{2}{*}{$\begin{array}{l}\text { Used as } \\
\text { reference }\end{array}$} \\
\hline & $\begin{array}{c}\text { Along } \\
\text { building } \\
\text { direction }\end{array}$ & 12.99 & 66.74 & 55.37 & 10.59 & & \\
\hline \multirow{2}{*}{ Sandblasted } & $\begin{array}{l}\text { Along } \\
\text { circumfer- } \\
\text { ence }\end{array}$ & 7.54 & 50.38 & 27.12 & 5.29 & \multirow{2}{*}{7.41} & \multirow{2}{*}{$43.2 \%$} \\
\hline & $\begin{array}{c}\text { Along } \\
\text { building } \\
\text { direction }\end{array}$ & 7.28 & 50.39 & 28.38 & 5.57 & & \\
\hline \multirow{2}{*}{ Turned } & $\begin{array}{l}\text { Along } \\
\text { circumfer- } \\
\text { ence }\end{array}$ & 2.74 & 3.02 & 0.88 & 0.13 & \multirow{2}{*}{2.75} & \multirow{2}{*}{$78.9 \%$} \\
\hline & $\begin{array}{c}\text { Along } \\
\text { building } \\
\text { direction }\end{array}$ & 2.76 & 2.76 & 1.10 & 0.15 & & \\
\hline
\end{tabular}

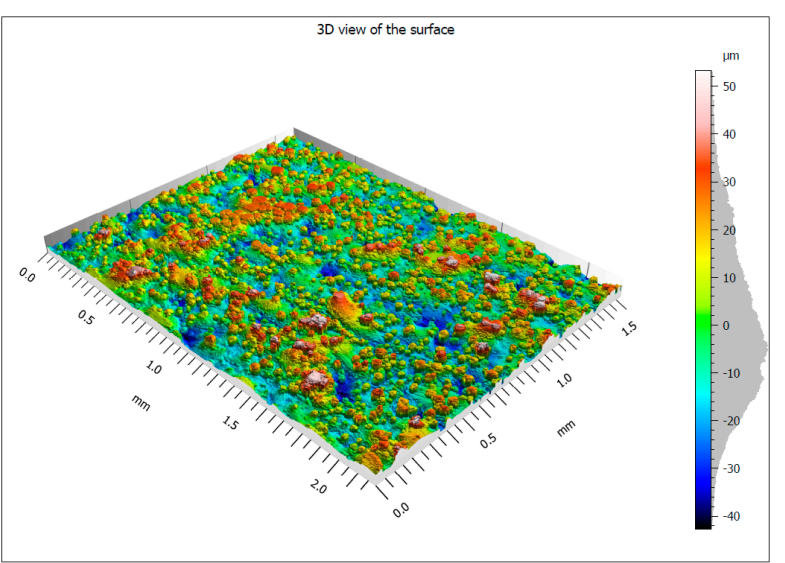

Figure 5. 3D surface roughness map for as-printed sample. 


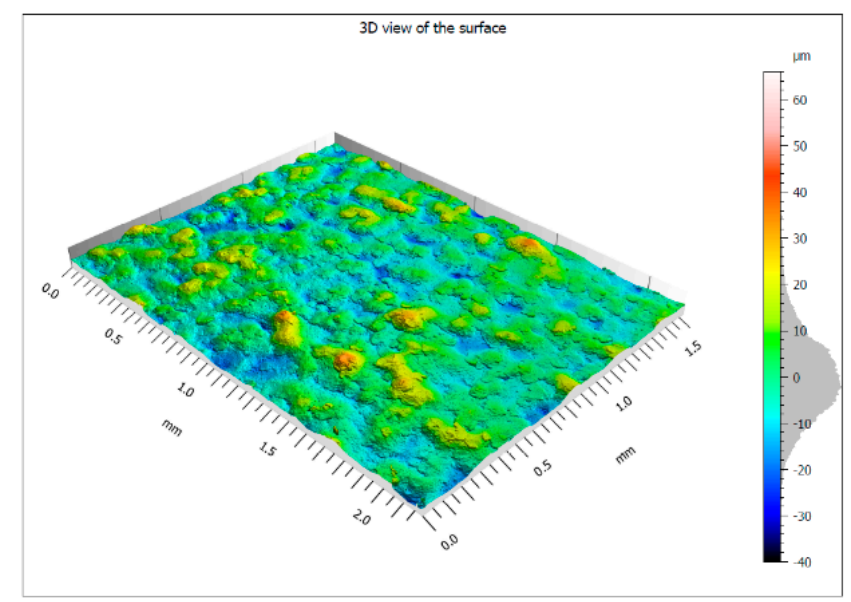

Figure 6. 3D surface roughness map for sandblasted sample.

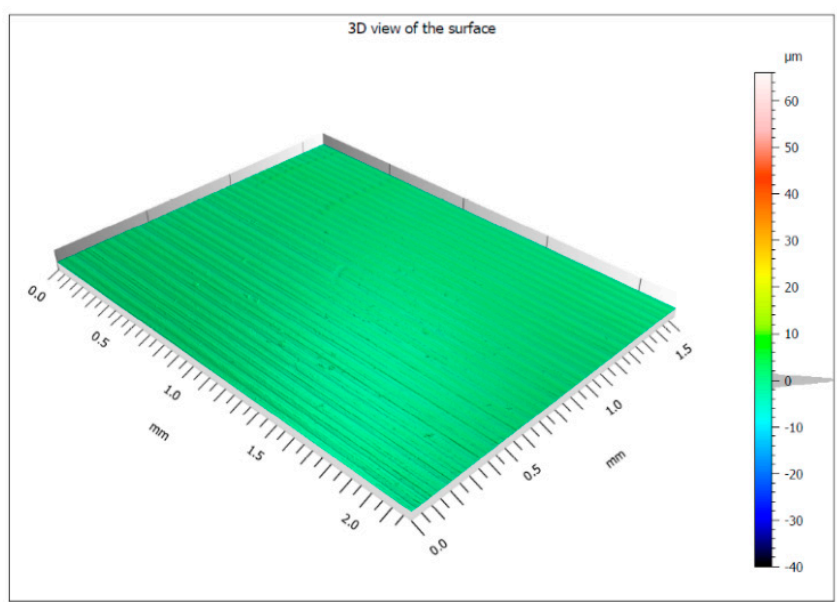

Figure 7. 3D surface roughness map for turned sample.

Table 5. Table showing final dimensions of cylinders. Average values after adjusting Vernier measurements for average surface roughness $S_{a}$ calculated from confocal microscopy.

\begin{tabular}{ccccc}
\hline S. No & Set & D $_{\mathbf{o}}($ in $\mathbf{~ m m})$ & $\mathbf{D}_{\mathbf{i}}(\mathbf{i n} \mathbf{~ m m})$ & Area (in $\left.\mathbf{~ m m}^{\mathbf{2}}\right)$ \\
\hline 1 & Set A & 24.81 & 22.79 & 75.40 \\
\hline 2 & Set B & 24.86 & 22.85 & 75.45 \\
\hline 3 & Set C & 24.86 & 22.86 & 74.73 \\
\hline 4 & Set D & 25.07 & 22.89 & 81.80 \\
\hline 5 & Set E & 25.07 & 22.90 & 81.70 \\
\hline 6 & Set F & 25.04 & 22.96 & 78.41 \\
\hline
\end{tabular}

As can be seen from the table above, the values are representative of an aspect ratio of at least 23:1, which qualifies as a thin-shell structure. The Sa-value was chosen as a true indicator of surface roughness for AM samples since it was reasoned that Ra-values do not represent true surface morphologies while considering the surface roughness (such as partially melted powder). As seen in Table 4, it can be observed that the surface finish improves drastically by post-AM surface treatment; there was up to a $79 \%$ reduction in measured surface roughness from as-printed to machined samples. 


\subsection{Microstructural Investigation of the Samples}

The microstructures of all types of samples were studied. Figure 8 illustrates the microstructures for one type of sample (Set D in Table 1). It is seen in the as-printed surface that the contour scanning forms overlapping melt pools, which are stacked together. It proves how contour scanning re-melts the region after bulk scanning. When the machined surface is compared with the as-printed surface, the surface microstructure is lost, since the turning removed about $3 \mathrm{~mm}$ of material from the original surface. Additionally, further EBSD scan for sample from Set D was conducted, as shown in Figure 9. It showed that the as-printed surface also consisted of the randomized texture of grains, which could originate from re-melting caused due to contour scanning.

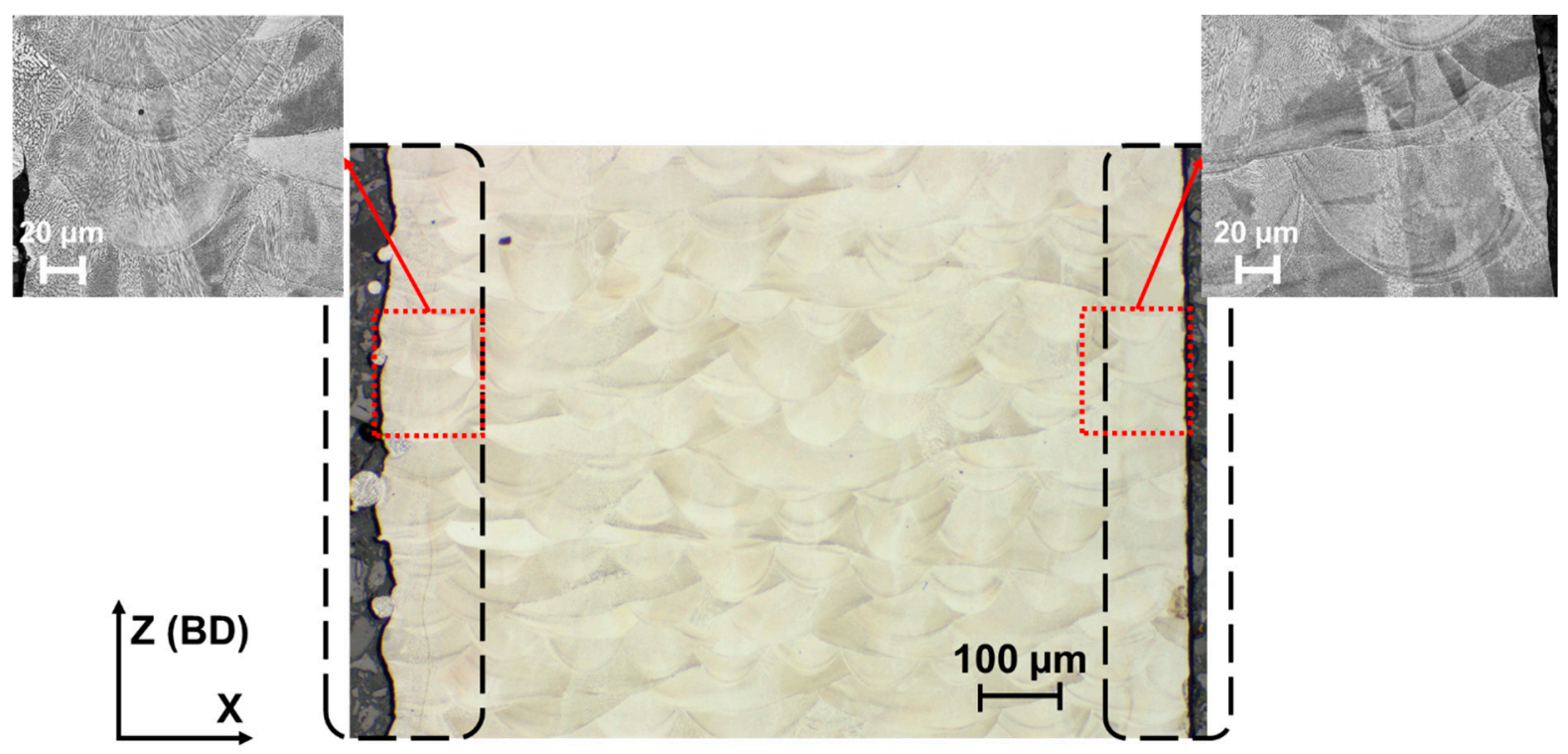

Figure 8. Low magnification image on an etched sample $(10 \times)$ showing as-printed surface on left side and turned surface on right side. Inset image on left side shows a magnified image $(50 \times)$ of the surface showing stacking of melt pools coming from contour scanning, which is removed after turning (as seen in inset image on right).

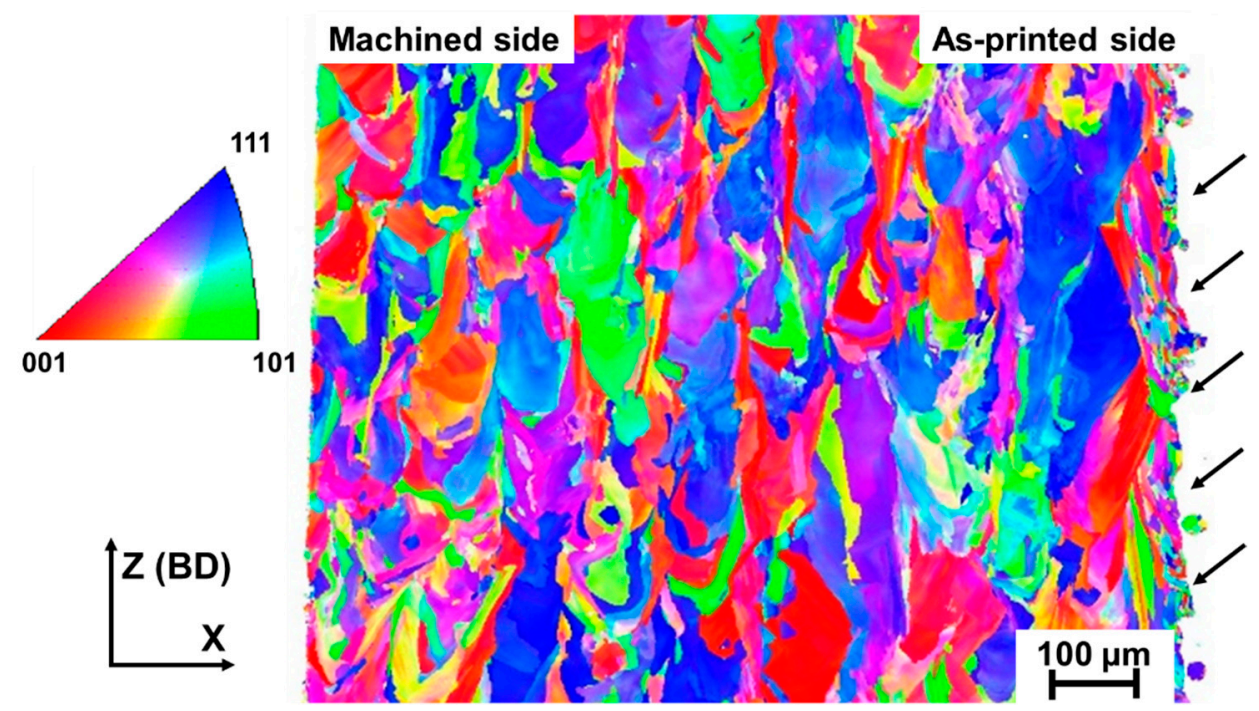

Figure 9. EBSD maps of similar sample as Figure 7 where a randomized texture is formed on the as-printed side. A possible reason could be due to re-melting caused by contour scanning. 


\subsection{Mechanical Testing}

All the 20 samples were tested in a uniaxial testing machine with a compression plate designed to avoid localized buckling at the top/bottom edges of the part. A cut section $C A D$ view and the compression setup in the uniaxial testing machine are shown in Figure 10.

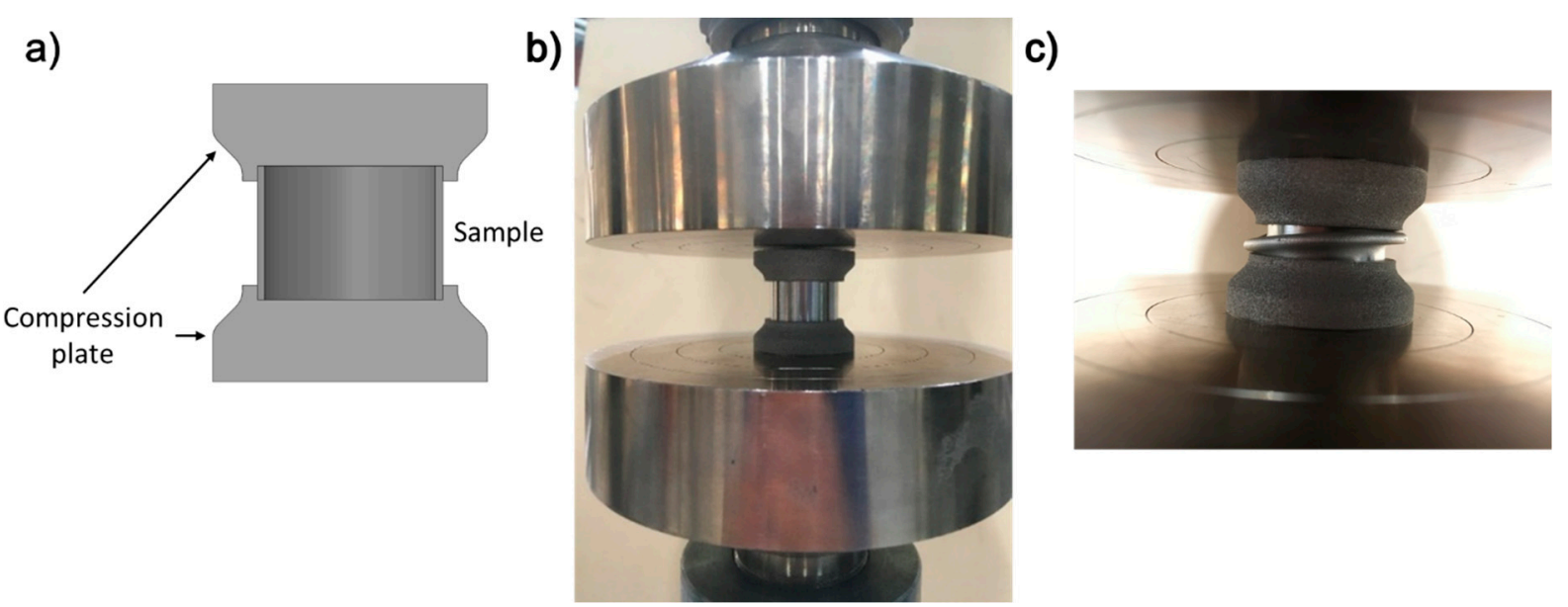

Figure 10. (a) Cut section CAD view of the assembly with two compression plates and (b) the actual assembly before loading in uniaxial testing machine. (c) Assembly after completing the test showing globalized buckling.

After the compression testing was concluded, the peak strength values were taken as maximum buckling load or yield point beyond which material failure occurred. The comparison in Figure 11 shows a gradual increase in average peak strength (or maximum buckling load if appropriate) with decreasing surface roughness. The peak strength shows a lower value after sandblasting as compared to turning (Set $\mathrm{A} \rightarrow \mathrm{C}$ as compared to Set $\mathrm{A} \rightarrow \mathrm{F}$ ). Overall, there were either marginal increase of $0.85 \%$ or more significant $6.5 \%$ increases in average peak strengths when comparing Set A (both sides as-printed condition) with Set $C$ (both sides sandblasted) and Set F (both sides turned), respectively. Hence, sandblasting leads to a negligible increase in peak strength, while turning away the surface layer on both faces increases the peak strength considerably. Improving surface finish alone by around $40 \%$ (shown in Table 4) tends to have a small effect on the assessed compressive peak strength, while the combined effect of further improving the surface finish and removing the surface layer completely significantly affects the compressive strength. In Table 6, the average peak strength values from all six sets have been summarized. It was observed that the standard deviation values were low, and positive/ negative deviation (error) was about one standard deviation. This suggests that the peak strength values are stable, and the strengthening effect from Set $\mathrm{A} \rightarrow \mathrm{F}$ is significant. Overall, the standard deviation values were quite small (approximately $2 \%$ of peak strength values).

Table 6. Average peak strength values $(\mathrm{MPa})$ for all six sets showing standard deviation.

\begin{tabular}{ccccc}
\hline Set & $\begin{array}{c}\text { Average Peak } \\
\text { Strength }(\mathbf{M P a})\end{array}$ & $\begin{array}{c}\text { Positive Error } \\
\mathbf{( M P a )}\end{array}$ & $\begin{array}{c}\text { Negative Error } \\
\mathbf{( M P a})\end{array}$ & $\begin{array}{c}\text { Standard Deviation } \\
\mathbf{( M P a})\end{array}$ \\
\hline Set A & 574.30 & 16.71 & 8.86 & 11.82 \\
\hline Set B & 575.45 & 9.89 & 9.42 & 7.89 \\
\hline Set C & 579.17 & 9.96 & 10.98 & 8.58 \\
\hline Set D & 605.78 & 18.15 & 17.57 & 14.59 \\
\hline Set E & 615.71 & 6.78 & 8.78 & 6.50 \\
\hline Set F & 611.63 & 33.93 & 25.46 & 19.37 \\
\hline
\end{tabular}




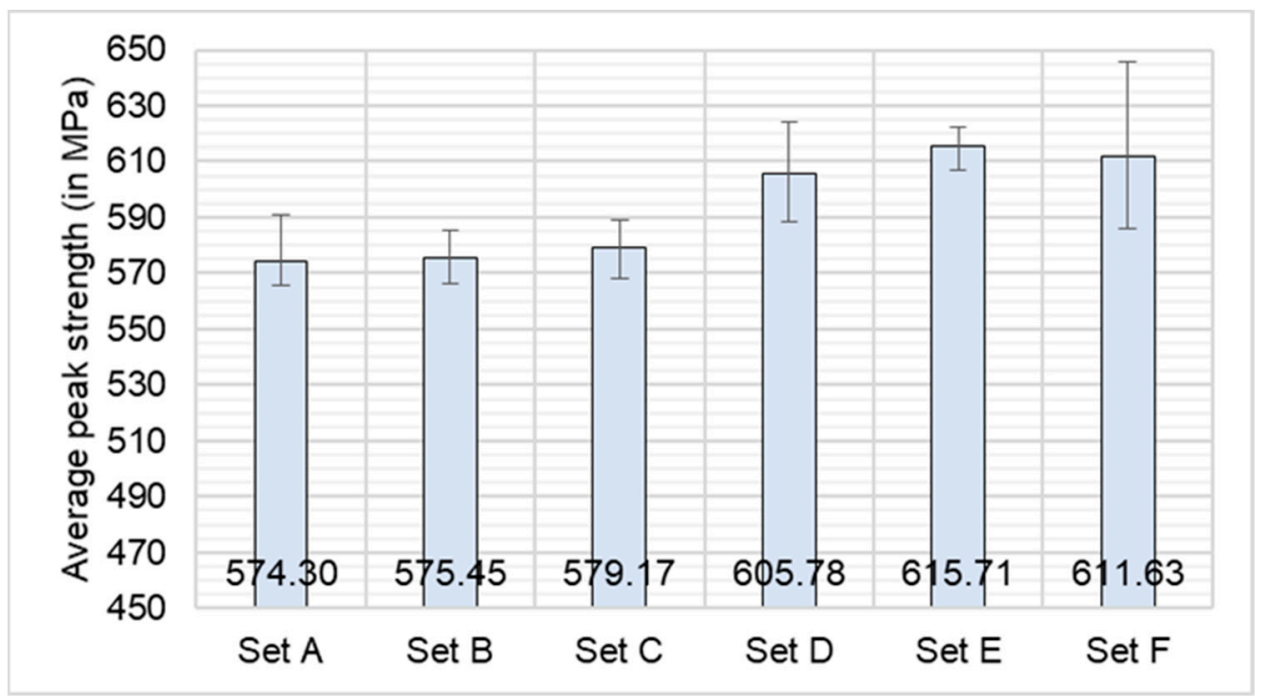

Figure 11. The average peak strength (in MPa) for different samples under uniaxial compression.

\section{Discussion}

The contour scanning deployed during the LB-PBF process to achieve better surface characteristics is a well-recognized method [22,23]. It is completed because the optimum parameters for achieving the best surface and bulk density are not the same. A different laser power to speed ratio is used at the surface to re-melt the already existing bulk to have a better surface finish $[22,24]$. This re-melting also causes a change in grain texture, thus proving a change in thermal history as compared to bulk specimen, as shown in Figure 9. This difference in processing parameters is required since a better surface quality is desired on the surface, and a near-dense part is required in the bulk. A better-quality surface is critical for improving mechanical properties such as fatigue resistance and elongation before failure in tensile loading, which are highly dependent on the quality of surface and surface/sub-surface defects $[17,25]$. However, creating better surfaces is not the only application for AM materials, and it may create limitations for other properties, such as compressive properties or a drop in yield resistance for thin-wall structures. It has been shown that a reduction in tensile yield strength is observed when the thickness of samples is reduced [14,15]. Further, to prove that contour scanning has a decisive role to play, Figure 11 clearly shows that just by improving the surface roughness (sandblasting), there is a negligible increase in compressive properties. It is only by removing the soft surface layer completely (set D-F) that the full strength of the material is realized.

In Figure 12, a schematic of the melt pool forming at the surface region is shown. It shows that contour scanning would cause re-melting of the surface region, thus letting the heat stay longer in those regions, causing a local softening effect. The generic effect of heat treatments to reduce dislocation densities in bulk AM materials has been shown before [5]. It was shown that there is a microhardness loss from $3.2 \pm 0.1 \mathrm{GPa}$ to $2.2 \pm 0.1 \mathrm{GPa}$ after annealing the samples at $1073 \mathrm{~K}$ for 6 min under Ar atmosphere. This resulting microhardness was similar to that of wrought solution annealed and cast 316L stainless steel, which is $2.1 \pm 0.1 \mathrm{GPa}$ [26]. Hence, this argumentation suggests that inherent heat treatments, such as the one caused by contour scanning on the surface melt pool, could lead to local softening of the surface zone. Considering the proposed surface layer model [12], where it is said that the dislocation structure close to the surface is different compared to that inside the part, it can be anticipated that this causes a local change in the plastic regime. Additionally, it is well-known that surface grain microstructure is usually depleted in dislocation density for thin samples which are conventionally manufactured [27], but that is again not necessarily the same mechanism as the thermal gradients and processing conditions in LB-PBF materials are quite different. In LB-PBF, heat is conducted away to 
the bottom of the part, as the part is usually covered by a powder bed known to conduct less heat than solid material [28].

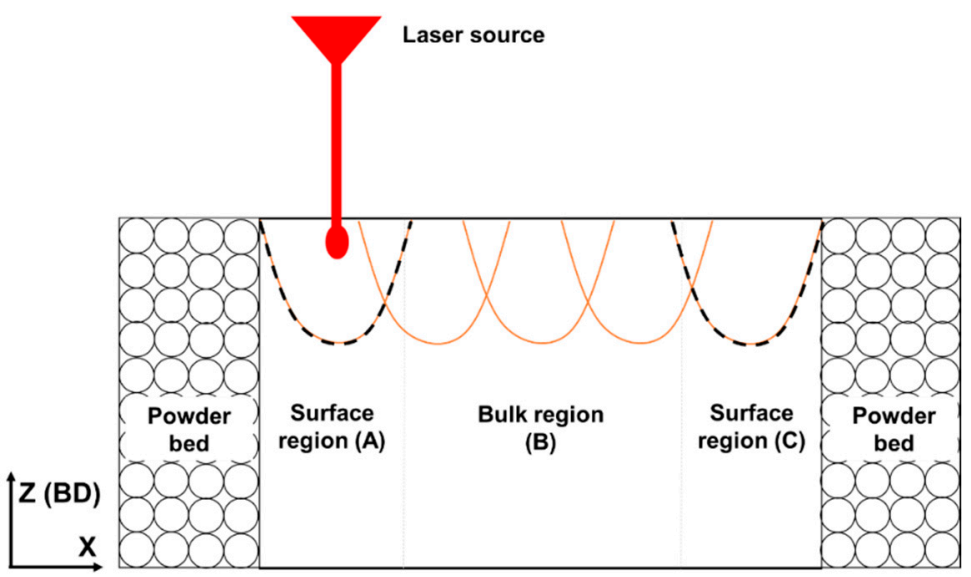

Figure 12. Illustration of melt pools at the surface and interior of a specimen. The bulk scanning (orange) happens once, whereas contour scanning (black, dotted) re-melts the surface melt pool, thus causing a softening effect.

Figure 13 shows a simple cross-section sketch of surface regions $(\mathrm{A}, \mathrm{C})$ and the bulk region (B). This division is made on an approximate basis as the average width of a melt pool is about $100-150 \mu \mathrm{m}$. This means that there are about 8-10 melt pools in a cross-section thickness of $1 \mathrm{~mm}$ (which was confirmed analytically in Figure 8). The surface treatments such as sandblasting and turning have different effects. Sandblasting would add residual stress to the surface grains, which may then become slightly hardened, whereas turning will get rid of the surface grains completely (seen in Figures 8 and 9) as the material removal was $3 \mathrm{~mm}$ to reach the same final dimensions as the as-printed sample compared with. The regions A, C are supposed to be the softened surface regions, depleted in dislocation density, thus having weaker load-bearing capacities as compared to region B. Now, it can be assumed that LB-PBF-fabricated 316L in terms of bulk properties can be viewed as a heavily deformed version of conventionally manufactured 316L owing to increased dislocation density. When a part such as this is loaded in compression, the plausible softer surface microstructure (regions A and C) constitutes a weaker loadbearing surface part, while the interior of the specimens, i.e., about $0.7-0.8 \mathrm{~mm}$ of actual microstructure, which is dislocation-hardened, displays the strongest load-bearing part. Hence, this kind of composite structure leads to a reduction in average peak strength (or load bearing properties) as compared to expected bulk values. This has been observed elsewhere [14], where the tensile yield strength also started to drop when specimens were reduced in section thickness, and a similar phenomenon could be the reason. When adding surface treatments to this loading condition, sandblasting supposedly creates a work-hardened surface, which should improve the properties of the surface [29,30], but the overall effect on compressive peak strength is limited as the blasting effect is normally shallow. It is suggested that the dislocation hardening of the bulk is still predominant in determining the overall compressive response, as seen by the only $0.85 \%$ increase in average peak strength from Sets $\mathrm{A} \rightarrow \mathrm{C}$, whereby the overall change in buckling behavior is not prominent. However, when the surface zone is removed completely via turning, only fully hardened bulk is left, whereby the whole cross-section can equally carry the load. This also means that the specimen should increase in load-bearing capacity when passing from section thickness of $0.8 \mathrm{~mm}-1 \mathrm{~mm}$, considering that the plausible soft surface zone is 0.1 to $0.15 \mathrm{~mm}$. To further depict potential effects of differences in dislocation, this would need further validation by means of, e.g., transmission electron microscopy (TEM) and assessment of dislocation movement via in situ heat treatment in a TEM with samples extracted from the surface and bulk of the specimen, which would represent the next 
stage in analysis for the research conducted. Another way forward could be to conducta nanoindentation testing, which develops hardness maps across thin cross-sections, thus providing localized hardening profiles.

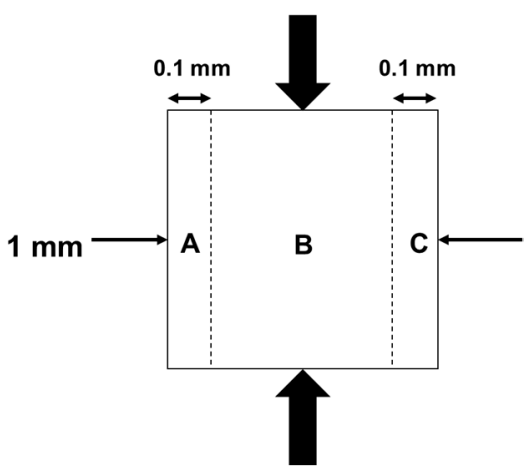

Figure 13. Illustration of the compression load along sample cross-section.

\section{Conclusions}

- Thin cylindrical shells were designed and manufactured for the LB-PBF process, aiming for application in buckling-resistant structures. The samples were given different surface treatments commonly applied after the LB-PBF process, such as sandblasting and manual turning (turning operation).

- An increased peak compressive strength was observed as compared to the as-printed specimen. A negligible increase was observed after sandblasting, whereas a $6.5 \%$ increase was observed after turning both the surface layers.

- This effect is then attributed to the contour scanning performed during the LB-PBF processing to ensure better surfaces and lower defects on the surface and sub-surface. Since contour scanning re-melts the bulk of the sample, it is suggested that this leads to softening of microstructure at the surface of the part.

- The results can be a good input for engineers when designing thin-walled structures where a certain aspect ratio is a necessity. CAD design should consequently accommodate for post-AM treatments to ensure full performance and not rely on bulk properties for the design of advanced structures.

Author Contributions: B.M.: Conceptualization, Methodology, Investigation, Writing-Original Draft, Project administration; E.H.: Conceptualization, Funding acquisition, Writing-Review and Editing, Supervision; L.N.: Conceptualization, Funding acquisition, Writing-Review and Editing, Supervision; E.J.: Resources, Supervision; F.T.: Investigation, Resources, Supervision. All authors have read and agreed to the published version of the manuscript.

Funding: The work was performed in the framework of the Centre for Additive Manufacturing-Metal (CAM2) hosted by Chalmers University of Technology, supported by VINNOVA (grant number: 2016-05175).

Data Availability Statement: Not Applicable.

Acknowledgments: The authors would like to acknowledge the support in terms of resources and funding from Centre of Additive Manufacturing- Metal (CAM2) hosted by Chalmers University of Technology, LIGHTer project (supported by VINNOVA) and Production Area of Advance at Chalmers University of Technology. The authors are grateful to Marie Fischer for her guidance in supervising during the MSc thesis and help in formulating some of the experiments, Alexander Leicht for his insightful discussions and help with the EBSD imaging, and Johan Ahlström for help with compression testing in Set F. At ABB Corporate Research, Daniel Morin for helping with the testing of the samples. At RISE Mölndal, Sebastian Proper is thanked for conducting surface roughness tests.

Conflicts of Interest: The authors declare no conflict of interest. 


\section{References}

1. ISO International. ASTM 52900: 2015 Additive Manufacturing; ISO International: Geneva, Switzerland, 2015.

2. DebRoy, T.; Wei, H.L.; Zubeck, J.S.; Mukherjee, T.; Elmer, J.W.; Milewski, J.O.; Beese, A.; Wilson-Heid, A.; De, A.; Zhang, W. Additive manufacturing of metallic components-Process, structure and properties. Prog. Mater. Sci. 2018, 92, 112-224. [CrossRef]

3. Frazier, W. Metal Additive Manufacturing: A Review. J. Mater. Eng. Perform. 2014, 23, 1917-1928. [CrossRef]

4. 316lproperties_EOS. 2014. Available online: https://cdn1.scrvt.com/eos/77d285f20ed6ae89/dd6850c010d3/EOSStainlessSteel3 16L.pdf (accessed on 10 March 2021).

5. Saeidi, K.; Gao, X.; Zhong, Y.; Shen, Z.J. Hardened austenite steel with columnar sub-grain structure formed by laser melting. Mater. Sci. Eng. A 2015, 625, 221-229. [CrossRef]

6. Wang, M.; Voisin, T.; McKeown, J.T.; Ye, J.; Calta, N.; Li, Z.; Zeng, Z.; Zhang, Y.; Chen, W.; Roehling, T.T.; et al. Additively Manufactured hierarchical stainless steels with high strength and ductility. Nat. Mater. 2018, 17, 63-70. [CrossRef] [PubMed]

7. Leicht, A. Laser Powder Bed Fusion of 316L Stainless Steel. Ph.D. Thesis, Chalmers University of Technology, Gothenburg, Sweden, 2020.

8. Feaugas, X. On the origin of the tensile flow stress in stainless steel AISI 316L at 300K: Back stress and effective stress. Acta Mater 1999, 47, 3617-3632. [CrossRef]

9. Yin, Y.J.; Sun, J.Q.; Guo, J.; Kan, X.F.; Yang, D.C. Mechanism of high yield strength and yield ratio of $316 \mathrm{~L}$ stainless steel by additive manufacturing. Mater. Sci. Eng. A 2019, 774, 773-777. [CrossRef]

10. Wang, Y.; Zhang, L.; Daynes, S.; Zhang, H.; Feih, S.; Wang, M.Y. Design of graded lattice structure with optimized mesostructures for additive manufacturing. Mater. Des. 2018, 142, 114-123. [CrossRef]

11. Park, S.-I.; Rosen, D.W.; Choi, S.-k.; Duty, C.E. Effective mechanical properties of lattice material fabricated by material extrusion additive manufacturing. Addit. Manuf. 2014, 1, 12-23.

12. Yang, L.; Lu, L. The influence of sample thickness on the tensile properties of pure Cu with different grain sizes. Scr. Mater. 2013, 69, 242-245. [CrossRef]

13. Hug, E.; Keller, C. Intrinsic Effects due to the Reduction of Thickness on the Mechanical Behavior of Nickel Polycrystals. Metall. Mater. Trans. A 2010, 41, 2498-2506. [CrossRef]

14. Leicht, A.; Pauzon, C.; Rashidi, M.; Klement, U.; Nyborg, L.; Hryha, E. Effect of part thickness on the microstructure and tensile properties of 316L parts produced by laser powder bed fusion. Adv. Ind. Manuf. Eng. 2021, 2, 100037.

15. Roach, A.; White, B.C.; Garland, A.; Jared, B.H.; Carroll, J.D. Size-dependent stochastic tensile properties in additively manufactured 316L stainless steel. Addit. Manuf. 2020, 32, 101090. [CrossRef]

16. Bagherifard, S.; Beretta, N.; Monti, S.; Riccio, M.; Bandini, M.; Guagliano, M. On the fatigue strength enhancement of additive manufactured AlSi10Mg parts by mechanical and thermal post-processing. Mater. Des. 2018, 145, 28-41. [CrossRef]

17. Bagehorn, S.; Wehr, J.; Maeir, H.J. Application of mechanical surface finishing processes for roughness reduction and fatigue improvement of additively manufactured Ti-6Al-4V parts. Int. J. Fatigue 2017, 102, 135-142. [CrossRef]

18. Khan, H.M.; Karabulut, Y.; Kitay, O.; Kaynak, Y.; Jawahir, I.S. Influence of the post-processing operations on surface integrity of metal components produced by laser powder bed fusion additive manufacturing: A review. Mach. Sci. Technol. 2021, 25, 118-176. [CrossRef]

19. Mehta, B. Enhanced Performance of Magnetic Floating Devices Enabled through Metal Additive Manufacturing; Chalmers University of Technology: Gothenburg, Spain, 2019.

20. Höganäs, A.B. AM 316L. Available online: https://www.hoganas.com/globalassets/download-media/sharepoint/brochuresand-datasheets---all-documents/additeve-manufacturing_am-3161_20-53_3045hog.pdf (accessed on 10 March 2021).

21. Timoshenko, S.P.; Gere, J.M. Theory of Elastic Stability; McGraw Hill International Book Company: New York, NY, USA, 1985.

22. Mohammadi, M.; Asgari, H. Achieving low surface roughness AlSi10Mg_200C parts using direct metal laser sintering. Addit. Manuf. 2018, 20, 23-32. [CrossRef]

23. Karimi, P.; Schnur, C.; Sadeghi, E.; Andersson, J. Contour design to improve topographical and microstructural characteristics of Alloy 718 manufactured by electron beam-powder bed fusion technique. Addit. Manuf. 2020, 32, 101014. [CrossRef]

24. Fox, J.C.; Moylan, S.P.; Lane, B.M. Effect of process parameters on the surface roughness of overhanging structures in laser powder bed fusion additive manufacturing. Procedia CIRP 2016, 131-134. [CrossRef]

25. Andreau, O.; Pessard, E.; Koutiri, I.; Penot, J.-D.; Dupuy, C.; Saintier, N.; Peyre, P. A competition between the contour and hatching zones on the high cycle fatigue behaviour of a $316 \mathrm{~L}$ stainless steel: Analyzed using X-ray computed tomography. Mater. Sci. Eng. A 2019, 757, 146-159. [CrossRef]

26. Ganesh, P.; Giri, R.; Kaul, R.; Sankar, P.R.; Tiwari, P.; Atulkar, A.; Porwal, R.K.; Dayal, R.K.; Kukreja, L.M. Studies on pitting corrosion and sensitization in laser rapid manufactured specimens of type 316L stainless steel. Mater. Des. 2012, 39, 509-521. [CrossRef]

27. Armstrong, R.W. On size effects in polycrystal plasticity. J. Mech. Phys. Solids 1961, 9, 196-199. [CrossRef]

28. Wei, L.C.; Ehrlich, L.E.; Powell-Palm, M.J.; Montgomery, C.; Beuth, J.; Malen, J.A. Thermal conductivity of metal powders for powder bed additive manufacturing. Addit. Manuf. 2018, 21, 201-208. [CrossRef] 
29. Arifvianto, B.; Widodo, T.D.; Mahardika, M.; Dewo, P.; Salim, U.A. Effect of cold working and sand blasting on the microhardness, tensile strength and corrosion resistance of AISI 3161 stainless steel. Int. J. Miner. Metall. Mater. 2012, 19, $1093-1099$.

30. Santa-aho, S.; Kiviluoma, M.; Jokiaho, T.; Gundgire, T.; Honkanen, M.; Lindgren, M.; Vippola, M. Additive Manufactured 316L Stainless-Steel Samples: Microstructure, Residual Stress and Corrosion Characteristics after Post-Processing. MDPI Met. 2021, $11,182$. 